\title{
Structural principles and classification of sulfosalts
}

\author{
By Y.TAKEUChi and R. SaDanaga
}

Mineralogical Institute, Faculty of Science, University of Tokyo, Hongo, Tokyo

\author{
(Received 12 May 1969)
}

\begin{abstract}
Auszug
Ein Überblick über die Dimensionen der Anionengruppe $\mathbf{T S}_{3}, \mathbf{T}=\mathbf{A s}, \mathbf{S b}$, $\mathrm{Bi}$, in Sulfosalzen ergibt für die Abstände $\mathrm{T}-\mathrm{S}$ bzw. $\mathrm{S}-\mathrm{T}-\mathrm{S} 2,26$ und $2,31 \AA$ für $\mathrm{AsS}_{3}, 2,46$ und 2,54 $\AA$ für $\mathrm{SbS}_{3}$ und 2,62 und 2,79 $\AA$ für $\mathrm{BiS}_{3}$. Unter Berücksichtigung der möglichen Deformationen der Bindungswinkel werden die Abstände S-S zu $3,4-3,6 \AA$ für $\mathrm{AsS}_{3}, 3,6-3,8 \AA$ für $\mathrm{SbS}_{3}$ und $3,8-4,1 \AA$ für $\mathrm{BiS}_{3}$ angenommen.

Aus den bisher bestimmten Strukturen von Sulfosalzen könnte gefolgert werden, daß das Strukturprinzip dieser Gruppe auf der räumlichen Beziehung zwischen den Koordinationspolyedern um die Metall- und die T-Atome beruht und daß die Radien dieser Atome als Maß für die Klassifikation dienen könnten. Aber die Radien, vor allem der Metallatome, lassen sich wegen der wechselnden Koordination dieser Atome nicht eindeutig angeben. Deshalb wurden statt der Atomradien versuchsweise die Hauptquantenzahlen der Valenzelektronen als Ordnungsgröße benutzt. Die Sulfosalze wurden in ein Diagramm mit dem Mittel aus den Hauptquantenzahlen $\bar{n}_{A}$ als Abszisse und der Summe dieser Quantenzahlen, dividiert durch die Summe der Hauptquantenzahlen der T-Atome, $\Sigma \bar{n}_{\mathrm{A}} / \Sigma n_{\mathrm{T}}$, eingetragen. Im Diagramm sind deutlich vier Gebiete zu erkennen, von denen ein jedes nur Strukturen eines gemeinsamen Bauschemas aufweist. Das eine Gebiet umfaßt kupferreiche Verbindungen und ist durch Verknüpfungen von $\mathrm{CuS}_{4}$-Tetraedern allein oder mit $\mathrm{TS}_{3}$-Pyramiden charakterisiert; das zweite hat hohen Silbergehalt und wird hauptsächlich durch die Bindungen der Silberatome bestimmt; die Strukturen des dritten Gebiets sind bleireich oder silberarm und nah verwandt mit der Bleiglanz-Struktur; das vierte Gebiet ent. hält Blei-Sulfosalze mit relativ hohem Gehalt an T-Atomen. Die Strukturen dieses Gebiets wurden auch in der Abhängigkeit von $n_{\mathrm{T}}$ (statt $\vec{n}_{\mathrm{A}}$ als Abszisse) klassifiziert; für sie sind die Größenunterschiede zwischen den Blei-Polyedern und den $\mathrm{TS}_{3}$-Pyramiden maßgebend.
\end{abstract}

\section{Abstract}

A survey on the dimensions of the $\mathrm{TS}_{3}$ anionic groups in sulfosalts was carried out, where $\mathrm{T}$ represents a trivalent atom such as $\mathrm{As}$, $\mathrm{Sb}$ or $\mathrm{Bi}$. The average lengths of $T-S$ non-bridge bonds and $S-T-S$ bridge bonds are respec- 
tively $2.26 \AA$ and 2.31 for $\mathrm{AsS}_{3}, 2.46$ and 2.54 for $\mathrm{SbS}_{3}$ and 2.62 and 2.79 for $\mathrm{BiS}_{3}$. After due consideration has been paid to possible deformations of bond angles, the $\mathrm{S}-\mathrm{S}$ edge lengths are estimated to fall in the ranges $3.4-3.6 \AA$ for $\mathrm{AsS}_{3}$, $3.6-3.8$ for $\mathrm{SbS}_{3}$ and 3.8-4.1 for $\mathrm{BiS}_{3}$.

From the structures of sulfosalts so far determined, it was concluded that the structural principle of the group is the dimensional relationship between coordination polyhedra around the metal atoms and those of $\mathbf{T}$ atoms, and accordingly the radii of these constituent atoms were considered to serve as effective measures for the classification. However, since the radii of metal atoms especially for various coordination states cannot be unambiguously defined, the use of the principal quantum numbers for the valence shells was proposed as a tentative measure of their atomic sizes. A diagram was then constructed of the average principal quantum number of metal atoms versus the total quantum number of the atoms divided by the total quantum number of the $\mathrm{T}$ atoms, and various sulfosalts were plotted in it. The diagram clearly indicated four distinct areas, each of which groups together species having a common structural scheme. The first area covers the sulfosalts containing copper in large amounts and characterized structurally by linked $\mathrm{CuS}_{4}$ tetrahedra or by a linkage of $\mathrm{CuS}_{4}$ and $\mathrm{TS}_{3}$; the second covers those with high silver contents and characterized by the bonds peculiar to silver atoms; the third covers those bearing $\mathrm{Pb}$ in large amounts and those with low silver contents, and having close relationship to the galena structure; the fourth covers the group of lead sulfosalts having relatively high contents of $\mathrm{T}$ atoms.

A similar method of classification was then applied to the lead sulfosalts of the fourth area. Their structural characteristics are discussed in terms of dimensional differences between lead polyhedra and $\mathrm{TS}_{3}$ pyramids.

\section{Introduction}

Sulfosalts comprise a group of minerals having the general formula $\mathrm{A}_{m} \mathrm{~T}_{n} \mathrm{X}_{p}$, in which the common elements are: as $\mathrm{A}: \mathrm{Ag}, \mathrm{Cu}, \mathrm{Pb}$; as $\mathrm{T}$ : $\mathrm{As}, \mathrm{Sb}, \mathrm{Bi}$; as $\mathrm{X}$ : S (Berry and Mason, 1959) ${ }^{1}$, and they can be regarded as salts of the sulfo-acids of trivalent arsenic, antimony or bismuth. In the crystal structures of these minerals, the trivalent atom $\mathrm{T}$ is coordinated by three sulfur atoms to form a low pyramid, with $\mathrm{T}$ at the vertex and three sulfur atoms at the basal corners. Such pyramids often constitute a complex group, finite or infinite, by sharing sulfur atoms; the independent pyramids or the complex groups are linked together by monovalent atoms such as $\mathrm{Ag}$ and $\mathrm{Cu}$ or divalent atoms such as $\mathrm{Pb}$ or by both kinds. The presence of the $\mathrm{TS}_{3}$ pyramids in the structure is, in fact, the feature that distinguishes a sulfosalt from a sulfide. For example, enargite might, at a glance, be thought, from its composition $\mathrm{Cu}_{3} \mathrm{AsS}_{4}$, to be a sulfosalt, but arsenic in

1 BERRY and MAson have given the general formula $\mathrm{A}_{m} \mathrm{~B}_{n} \mathrm{C}_{p}$. However $\mathrm{B}$ is here replaced by $\mathbf{T}$ simply to avoid confusion with boron. 
this compound is pentavalent and takes a tetrahedral coordination of sulfur atoms, thus exhibiting the aspect of a derivative from wurtzite. This species should therefore be classified as a sulfide. On the other hand, the minerals of tetrahedrite series, $\mathrm{Cu}_{12}(\mathrm{As}, \mathrm{Sb})_{4} \mathrm{~S}_{13}$, are often misconceived as derivatives of the sphalerite structure. However, arsenic and antimony in these minerals are trivalent and have the pyramidal coordination characteristics of sulfosalts. In fact, as pointed out by WUENSCH (1964), the crystal structure of tetrahedrite cannot be derived directly from the sphalerite structure through the substitution of $\mathrm{Zn}$ by $\mathrm{Cu}$ and $(\mathrm{As}, \mathrm{Sb})$.

In the structure of a sulfosalt the presence of anionic groups, either single or polymerized, reminds us of the structure of a silicate in which $\mathrm{SiO}_{4}$ tetrahedra play a similar role. However, there is a difference between these two structures; the interatomic bonds in the silicate are essentially ionic, while those in sulfosalts are covalent, which means that the former are non-directional and simple, while the latter are directional and a little more complex. Certainly due to this fact, the classification of sulfosalts on the basis of their structural principles has not been established. However, since a number of important members of this group, especially those containing $\mathrm{Cu}$ and $\mathrm{Pb}$, have been investigated and their structures have been determined at least in their main features, it is believed that we should now direct our efforts to the problem of their classification.

In the present paper, we shall begin with a general survey of the dimensions of the $\mathrm{TS}_{3}$ group and propose principles for classification. Then we shall describe their application to the structures of sulfosalts containing $\mathrm{Pb}$ as the major metal atom, and discuss general structural scheme of these sulfosalts based upon the dimensional relations between $\mathrm{TS}_{3}$ pyramids and metal polyhedra.

\section{Dimensions of the $\mathrm{TS}_{3}$ anionic groups}

A survey of bond lengths in the structures of sulfides in general was lately carried out by BERRY (1965) and the bond lengths between trivalent atoms and sulfur atoms were also discussed. Since then, however, accurate structure determinations have been accomplished of some important members of sulfosalts, and more reliable data are now available. Therefore, it will be worthwhile revising and extending the survey. In the following, only those data from well-refined structures are employed, and bridge bonds of the S-T-S type and non-bridge 
Table 1. As-S bond lengths in sulfosalts

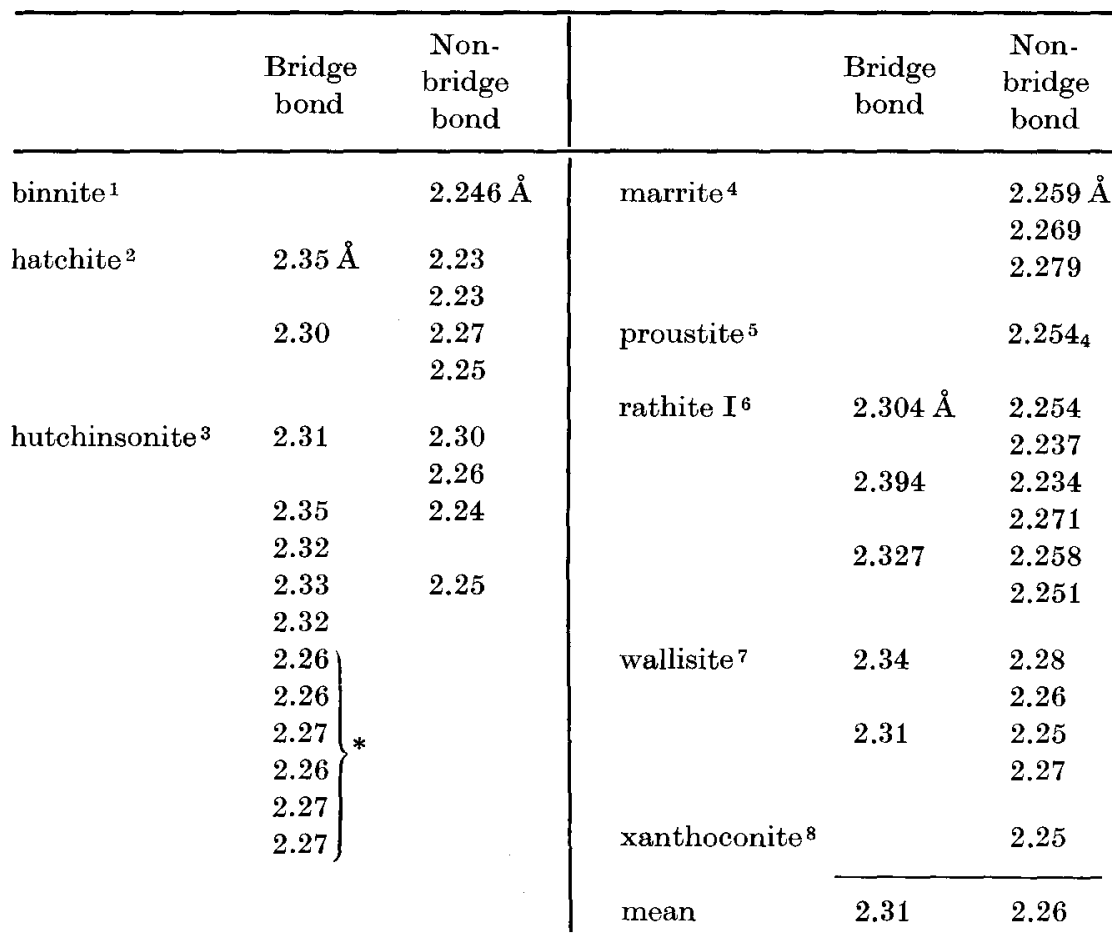

* Bond lengths in the As $-\mathrm{S}$ sheet configuration of hutchinsonite.

1 Wuensch et al. (1966), 2 Marumo and Nowacki (1967),

3 TAKḱUChi et al. (1965), 4 WUENSCh and Nowacki (1967),

5 Engel and Nowacki (1966), ${ }^{6}$ Marumo and Nowacki (1966),

7 TAKÉUChI et al. (1968), 8 ENGel and NowaCki (1968).

bonds $\mathrm{T}-\mathrm{S}$ will be given separate treatments because these two types of bond have revealed a marked difference in length.

Bond lengths between As and $\mathrm{S}$ are listed in Table 1. It will be noticed that bridge bonds are longer than non-bridge bonds. Some of the bridge bonds in hutchinsonite (TAKÉUCHI et al., 1965) are shorter than those of the rest in the table. In the structure of hutchinsonite some of the $\mathrm{AsS}_{3}$ pyramids form a sheet by sharing every sulfur corner, and the shorter bonds are found in this sheet. The bridge bonds in orpiment, $\mathrm{As}_{2} \mathrm{~S}_{3}$, whose structure is built up of a sheet of $\mathrm{AsS}_{3}$ pyramids, also show similar values ranging from $2.21 \AA$ to $2.28 \AA$ (Morimoto, 1954 ), giving a mean value of $2.25 \AA$. Thus it seems certain that the bridge bonds in a sheet are shorter than the others, though the reason 
Table 2. $S b-S$ bond lengths in sulfosalts

\begin{tabular}{|c|c|c|c|c|c|}
\hline & $\begin{array}{c}\text { Bridge } \\
\text { bond }\end{array}$ & $\begin{array}{l}\text { Non- } \\
\text { bridge } \\
\text { bond }\end{array}$ & & $\begin{array}{c}\text { Bridge } \\
\text { bond }\end{array}$ & $\begin{array}{c}\text { Non- } \\
\text { bridge } \\
\text { bond }\end{array}$ \\
\hline \multirow[t]{4}{*}{ berthierite ${ }^{1}$} & $2.58 \AA$ & $2.48 \AA$ & livingstonite ${ }^{3}$ & $2.47 \AA$ & \multirow[t]{8}{*}{$2.55 \AA$} \\
\hline & 2.58 & & & 2.62 & \\
\hline & 2.48 & \multirow[t]{2}{*}{2.43} & & \multirow{2}{*}{$\left.\begin{array}{l}2.59 \\
2.54\end{array}\right)$} & \\
\hline & 2.48 & & & & \\
\hline \multirow{11}{*}{ jamesonite ${ }^{* 2}$} & 2.64 & \multirow[t]{2}{*}{2.39} & & 2.66 & \\
\hline & 2.49 & & & 2.52 & \\
\hline & 2.52 & \multirow[t]{2}{*}{2.41} & & $\begin{array}{l}2.44 \\
2.47\end{array}$ & \\
\hline & 2.53 & & & & \\
\hline & 2.44 & \multirow[t]{7}{*}{2.42} & \multirow[t]{4}{*}{ miargyrite $^{4}$} & 2.49 & 2.48 \\
\hline & 2.79 & & & 2.54 & \\
\hline & & & & 2.53 & 2.58 \\
\hline & & & & 2.58 & \\
\hline & & & \multicolumn{2}{|l|}{ pyrargyrite $^{5}$} & $2.46_{3}$ \\
\hline & & & \multicolumn{2}{|l|}{ tetrahedrite $^{6}$} & 2.446 \\
\hline & & & mean & 2.54 & 2.46 \\
\hline
\end{tabular}

* Bond lengths were recalculated by the present authors.

** Bond lengths in the $\mathrm{Sb}-\mathrm{S}$ sheet configuration of livingstonite.

1 Buerger and HaHN (1955), 2 Nitzekr and Buerger (1957b),

${ }^{3}$ Nirzeki and Buerger (1957a), ${ }_{4}$ Knowles (1964),

5 Engel and Nowacki (1966), ${ }^{6}$ Wuensch (1964).

is unknown. On the other hand, Camerman and Trotter (1964) reported that the AsIII-S single bond in cacodyl disulfide shows a length of $2.28 \AA$ which falls between the mean value of bridge-bond lengths and that of non-bridge bonds in Table 1. However, the sulfur atom in this compound is bonded to one more arsenic atoms in the pentavalent state and accordingly forms a bridge bond, $\mathrm{As} \mathrm{s}^{\mathrm{II}}-\mathrm{S}-\mathrm{As} \mathrm{s}^{\mathrm{v}}$. The deviation from our values may therefore be due to this particular situation.

Bonds between $\mathrm{Sb}$ and $\mathrm{S}$ given in Table 2 indicate a larger difference in length between bridge bonds and non-bridge bonds than for As-S bonds. As in the case of hutchinsonite, the bridge bonds in a sheet of linked $\mathrm{SbS}_{3}$ in livingstonite (NIIZEKI and BUERGER, 1957a) are shorter than the average.

The differences in length between bridge bonds and non-bridge bonds are still larger in sulfbismuthites. The only well-refined structure 
Table 3. Bi-S bond lengths in sulfosalts

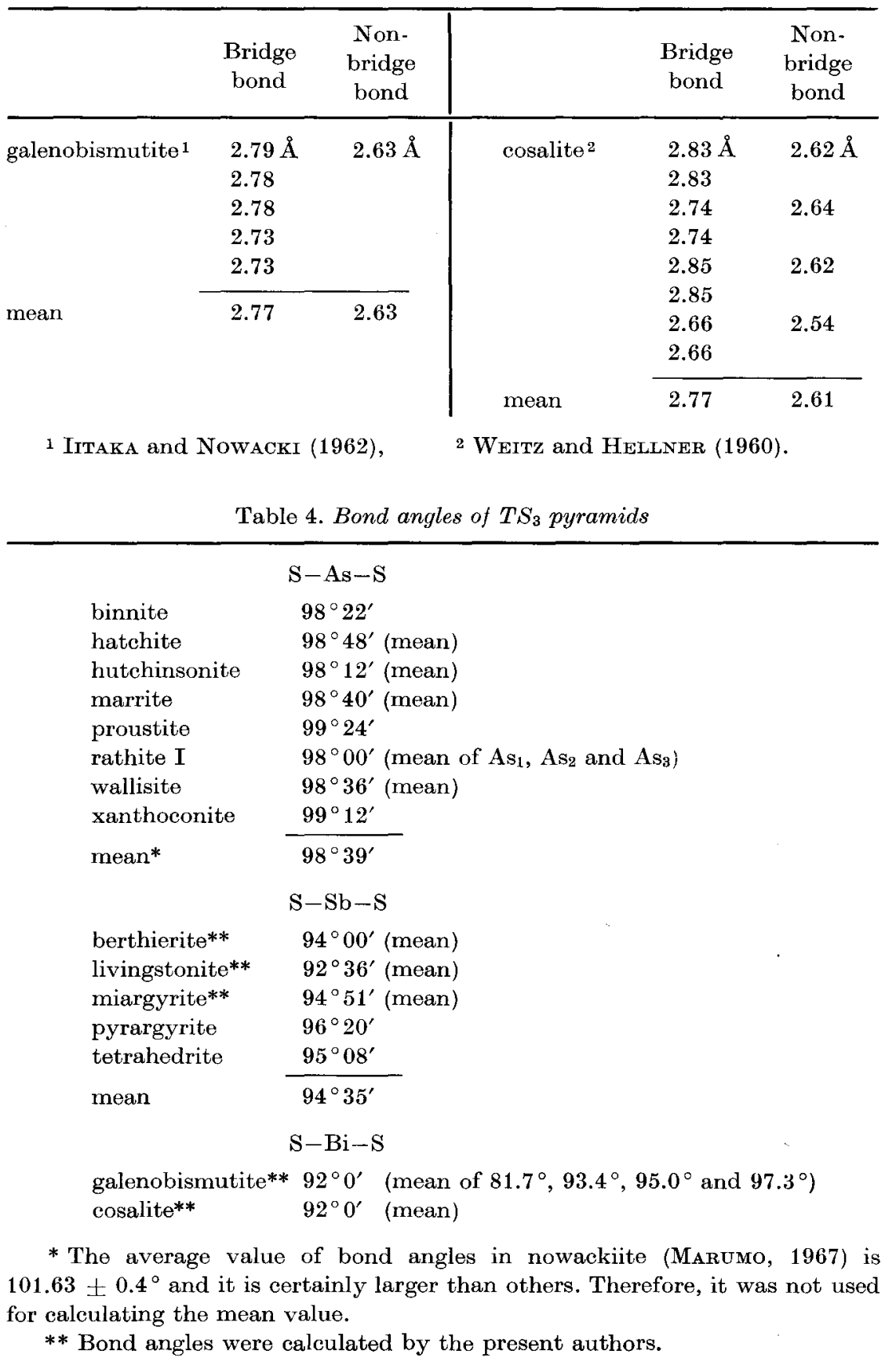


of this group is galenobismutite (IITAKa and NowaCki, 1962), data for which are given in Table 3, together with those of the less refined structure of cosalite (WEITZ and HeLLNER, 1960).

From the results of the above survey, we can conclude that for a certain kind of trivalent atom, the average length of bridge bonds is certainly greater than that of non-bridge bonds. Another conclusion to be drawn here is that the difference in length between bridge bonds and non-bridge bonds becomes larger with increasing atomic number of the trivalent atom, T. These facts are similar to those for the bonds

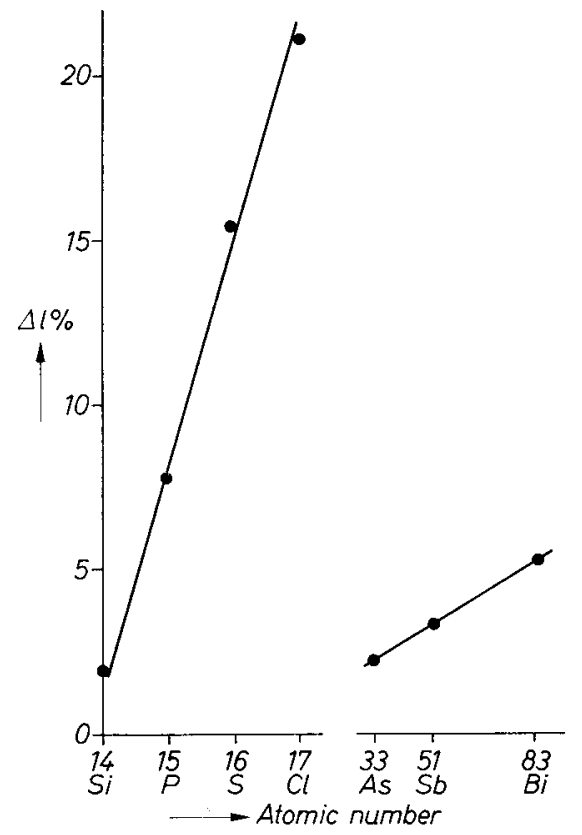

Fig. 1. Variations of the differences, $\Delta l$, between bridge bonds and non-bridge bonds in $\mathrm{TS}_{3}$ groups $(\mathrm{T}=\mathrm{As}, \mathrm{Sb}, \mathrm{Bi})$, and in $\left(\mathrm{XO}_{4}\right)^{n-}$ ions $(\mathrm{X}=\mathrm{Si}, \mathrm{P}, \mathrm{S}, \mathrm{Cl})$

in $\left(\mathrm{XO}_{4}\right)^{n-}$ ions $(\mathrm{X}=\mathrm{Si}, \mathrm{P}, \mathrm{S}$ or $\mathrm{Cl}$ ) as discussed by Cruickshank (1964). A quantity $\Delta l$ can be defined as (length of bridge bond-length of non-bridge bond)/(length of non-bridge bond). The average value of $\Delta l$ for each $\mathrm{T}-\mathrm{S}(\mathrm{T}=\mathrm{As}, \mathrm{Sb}, \mathrm{Bi})$ was evaluated and plotted in Fig. 1 together with that of each $\mathrm{X}-\mathrm{O}^{2}$. As observed in this figure $\Delta l$ of the $\mathrm{T}-\mathrm{S}$ bonds shows a linear variation with atomic number similar to that of $\left(\mathrm{XO}_{4}\right)^{n-}$ ions.

2 Calculated from the data appearing in CRUiCKshank (1964). 
Because of the $p$-orbital nature of the bonds in $\mathrm{TS}_{3}$ groups, the bond angles are expected to approach $90^{\circ}$ as the bond lengths between $\mathrm{T}$ and $\mathrm{S}$ increase. As seen in Table 4, this relation does hold for the $\mathrm{TS}_{3}$ groups. Thus, as reasonable measures for dimensions of the $\mathrm{TS}_{3}$ groups, the following values may be proposed:

$$
\begin{aligned}
& \begin{array}{lll}
\mathrm{AsS}_{3} & \mathrm{SbS}_{3} & \mathrm{BiS}_{3}
\end{array}
\end{aligned}
$$

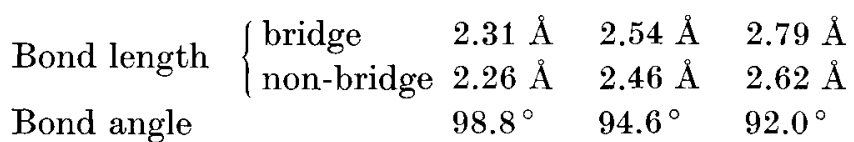

Next, we shall refer to $\mathrm{S}-\mathrm{S}$ edge lengths in the $\mathrm{TS}_{\mathbf{3}}$ groups where we must take possible deformation of bond angles into account. If two pyramids share an edge, the bond angles concerned will become smaller, while if a pyramid shares an edge with a coordination polyhedron (around lead for example) the bond angle concerned will become larger. After due consideration has been paid to these circumstances, the $\mathrm{S}-\mathrm{S}$ edge lenths are estimated to fall in the ranges: 3.4-3.6 $\AA$ for $\mathrm{AsS}_{3}, 3.6-3.8 \AA$ for $\mathrm{SbS}_{3}$, and 3.8-4.1 $\AA$ for $\mathrm{BiS}_{3}$.

So far we have taken into account the three shortest distances between $\mathrm{T}$ and $\mathrm{S}$ in the $\mathrm{TS}_{3}$ group with the assumption that the bonds involved are solely of $p$-orbital character. However, the facts revealed by the crystal structure of stibnite, $\mathrm{Sb}_{2} \mathrm{~S}_{3}$, should also be considered. According to ŠćavNIčAR (1960), the structure contains a ribbon-like configuration with the composition $\mathrm{Sb}_{4} \mathrm{~S}_{6}$. Two kinds of $\mathrm{Sb}$ atoms, $\mathrm{Sb}(1)$ and $\mathrm{Sb}(2)$, exist in a ribbon. $\mathrm{Sb}(1)$ is surrounded by three sulfur atoms and $\mathrm{Sb}(2)$ by five. Therefore, the bonds for $\mathrm{Sb}(1)$ are presumably of $p$ character, the $\mathrm{Sb}-\mathrm{S}$ distances being $2.58 \AA$ for bridge bonds and $2.57 \AA$ for non-bridge ones and the mean bond angle, $91.43^{\circ}$. For $\mathrm{Sb}(2)$, SćavNIčar assumed octahedral $s p^{3} d^{2}$ orbitals in which a pair of electrons forms a lone pair. The five sulfur atoms thus constitute a square pyramid with an antimony atom situated roughly at the centre of the basal square. The distances from $\mathrm{Sb}(2)$ to two basal sulfur atoms are $2.68 \AA$; to the other two basal atoms $2.82 \AA$; and to the apical atom $2.49 \AA$; and the mean bond angle is $89.19^{\circ}$. This fact suggests that some of the T-S bonds in sulfosalts may also be of octahedral character. As a matter of fact, five coordination around antimony can be noticed in the structure of berthierite, $\mathrm{FeSb}_{2} \mathrm{~S}_{4}$ (BUERGER and HAHN, 1955) and livingstonite, $\mathrm{HgSb}_{4} \mathrm{~S}_{8}$ (NIIZEKI and BUERgER, 1957a), though three sulfur atoms of the five are appreciably nearer to anti- 
mony than those in the case of stibnite. If the octahedral orbitals are involved in $\mathbf{T}-\mathbf{S}$ bonds, the $\mathbf{T}$ atom is expected to be surrounded by seven sulfur atoms as shown in Fig. 2, because repulsion arises between the lone-pair electrons and the sulfur atoms, and in fact, those antimony atoms in stibnite, berthierite and livingstonite have seven neighbouring sulfur atoms.
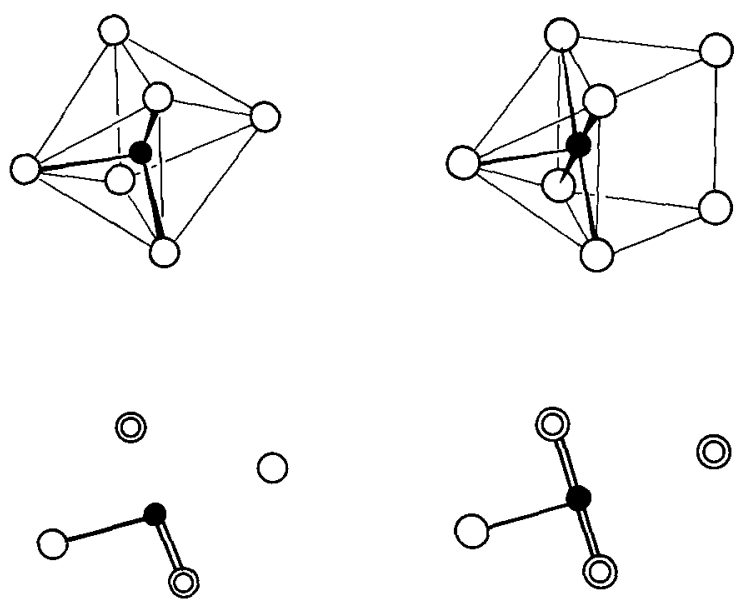

Fig. 2. Octahedral neighbours of a $\mathrm{TS}_{3}$ group which utilizes $p^{3}$ orbitals (left), and seven neighbours of sulfur atoms around a T atom which utilizes $s p^{3} d^{2}$ orbitals (right). The lower figures indicate the projections of each polygon along its vertical edges

On the other hand, in addition to $p^{3}$ orbitals, tetrahedral $s p^{3}$ orbitals are also possible in certain sulfosalts. The bond angles of $\mathrm{SbS}_{3}$ pyramids in chalcostibite, $\mathrm{CuSbS}_{2}$ (HoFManN, 1933), suggest that the bonds are of tetrahedral character, where a pair of electrons forms a lone pair.

\section{Classification of sulfosalts}

In order to classify the sulfosalts, we must first establish what principles govern the general relationship between the chemical compositions and the crystal structures of this group of minerals. As far as our survey of all the refined structures is concerned, we believe that the principle determining the structure is the dimensional relationship between the coordination polyhedra around monovalent and divalent metal atoms which we shall call 'A atoms' hereafter, and those around trivalent atoms which we shall call ' $\mathrm{T}$ atoms'. Accordingly, the radii of 
these constituent atoms can be considered as effective parameters for the classification. This will be exemplified in the subsequent section on the structures of the $\mathrm{Pb}$-bearing members.

On the other hand, however, the radii of these atoms for various coordination states cannot unambiguously be determined. Therefore, we here propose as tentative measures of their atomic sizes the principal quantum numbers of the valence shells of these atoms.

Since there are a number of sulfosalts which contain two, or more than two, kinds of $\mathrm{A}$ atoms, we introduce the 'average principal quantum number', $\bar{n}(\mathrm{~A})$, defined as

$$
\bar{n}(\mathrm{~A})=\Sigma k_{i} \cdot n\left(A_{i}\right) / \Sigma k_{i},
$$

where $n\left(A_{i}\right)$ is the principal quantum number for the valence shell of an $\mathrm{A}$ atom of the kind $i$, and $k_{i}$ is the number of the atoms per formula unit. The quantity, $\bar{n}(\mathrm{~A})$, will thus be a measure of the average size of A atoms existing in a structure. This parameter will also be used as a measure of the directional character of metal atoms involved in a structure (Pearson, 1964).

Next, we take a ratio, $\Sigma n\left(\mathrm{~A}_{i}\right) / \sum n\left(\mathrm{~T}_{j}\right)$, where $n\left(\mathrm{~T}_{j}\right)$ indicates the principal quantum number for the valence shell of a $T$ atom of the kind $j$, and summations should be made for the formula unit. This ratio is intended to serve as an indication of the volume occupied by A atoms relative to that occupied by $\mathrm{T}$ atoms in the structure under consideration. A diagram of $\vec{n}(\mathrm{~A})$ vs. $\sum n\left(\mathrm{~A}_{i}\right) / \sum n\left(\mathrm{~T}_{j}\right)$ was then prepared and the natural crystalline phases of sulfosalts were plotted (Fig. 3). As will be observed, this diagram is roughly divided into four parts according to the structural characteristics of the crystalline phases.

Area I covers the sulfosalts which contain copper as a major component. The crystal structures of sulfosalts which fall in this area are thus characterized by the linkages of $\mathrm{Cu}$ tetrahedra (e.g. tetrahedrite) or those of $\mathrm{Cu}$ tetrahedra and $\mathrm{TS}_{3}$ pyramids (e.g. chalcostibite). At the right of this area, there is located a group of sulfosalts-seligmannite, $\mathrm{PbCuAsS}_{3}$; bournonite, $\mathrm{PbCuSbS}_{3}$, and aikinite, $\mathrm{PbCuBiS}_{3}$. Hellner and LEINEWEBER (1956) showed that they have similar structures and pointed out the similarity between their structures and that of stibnite. However, TAKÉUCHI and HAGA (1969) refined the atomic parameters of seligmannite using the structure amplitudes given by LEINEWEBER (1956), and proposed a new view that it is essentially built up of a three-dimensional framework consisting of $\mathrm{CuS}_{4}$ tetrahedra and $\mathrm{AsS}_{3}$ 


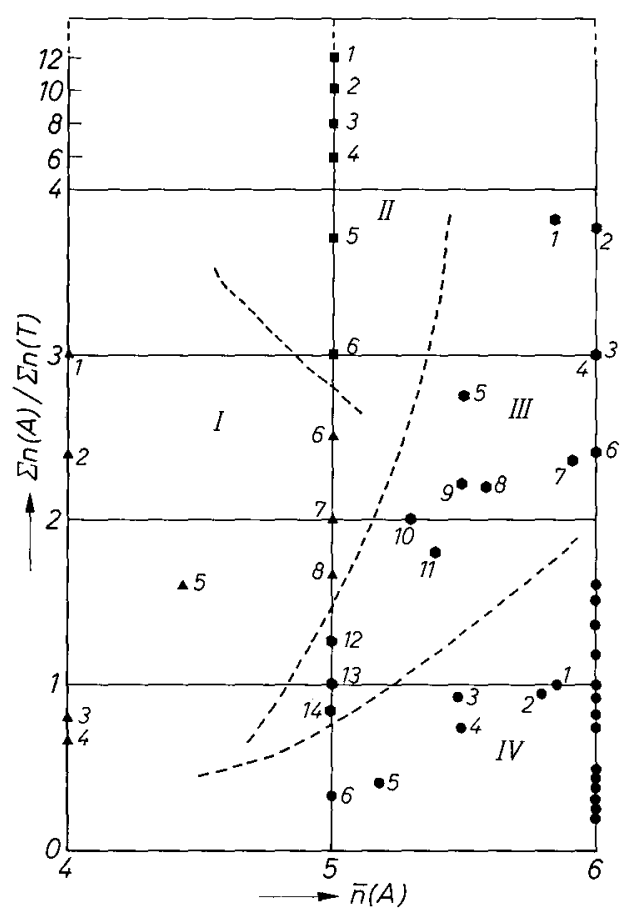

Fig. 3. The relations between the chemical compositions and the crystal structures of sulfosalts. Representative minerals in each area are:

Area I

1 binnite, $(\mathrm{Cu}, \mathrm{Fe})_{12} \mathrm{As}_{4} \mathrm{~S}_{13}$

2 tetrahedrite, $(\mathrm{Cu}, \mathrm{Fe})_{12} \mathrm{Sb}_{4} \mathrm{~S}_{13}$

3 chalcostibite, $\mathrm{CuSbS}_{2}$

4 emplectite, $\mathrm{CuBiS}_{2}$

5 berthonite, $\mathrm{Pb}_{2} \mathrm{Cu}_{7} \mathrm{Sb}_{5} \mathrm{~S}_{13}$

6 seligmannite, $\mathrm{PbCuAsS}_{3}$

7 bournonite, $\mathrm{PbCuSbS}_{3}$

8 aikinite, $\mathrm{PbCuBiS}_{2}$

\section{Area II}

1 polyargyrite, $\mathrm{Ag}_{24} \mathrm{Sb}_{2} \mathrm{~S}_{15}$ ?

2 pearceite, $(\mathrm{Ag}, \mathrm{Cu})_{16} \mathrm{As}_{2} \mathrm{~S}_{11}$

3 polybasite, $(\mathrm{Ag}, \mathrm{Cu})_{16} \mathrm{Sb}_{2} \mathrm{~S}_{11}$

4 stephanite, $\mathrm{Ag}_{5} \mathrm{SbS}_{4}$

5 xanthoconite, $\mathrm{Ag}_{3} \mathrm{AsS}_{3}$

6 pyrargyrite, $\mathrm{Ag}_{3} \mathrm{SbS}_{3}$

Area III

1 lengenbachite, $\mathrm{Pb}_{36} \mathrm{Ag}_{7} \mathrm{Cu}_{6} \mathrm{As}_{23} \mathrm{~S}_{78}$

2 gratonite, $\mathrm{Pb}_{9} \mathrm{As}_{\mathrm{s}_{4}} \mathrm{~S}_{15}$

Details of the mineral species on the vertical axis of $\ddot{n}(\mathrm{~A})=6$ in the area IV
3 geocronite, $\mathrm{Pb}_{5}(\mathrm{Sb}, \mathrm{As})_{2} \mathrm{~S}_{8}$

4 beegerite, $\mathrm{Pb}_{6} \mathrm{Bi}_{2} \mathrm{~S}_{9}$

5 marrite, $\mathrm{PbAgAsS} 3$

6 jordanite, $\mathrm{Pb}_{13} \mathrm{As}_{7} \mathrm{~S}_{23}$

7 meneghinite, $\mathrm{Pb}_{13} \mathrm{CuSb}_{7} \mathrm{~S}_{23}$

8 hatchite, $\mathrm{TlPbAgAs} 2 \mathrm{~S}_{5}$

9 freieslebenite, $\mathrm{PbAgSbS}_{3}$

10 wallisite, $\mathrm{TlPbCuAs} 2 \mathrm{~S}_{5}$

11 diaphorite, $\mathrm{Pb}_{2} \mathrm{Ag}_{3} \mathrm{Sb}_{3} \mathrm{~S}_{8}$

12 smithite, $\mathrm{AgAsS}_{2}$

13 miargyrite, $\mathrm{AgSbS}_{2}$

14 matildite, $\mathrm{AgBiS}_{2}$

\section{Area IV}

1 ramdohrite, $\mathrm{Pb}_{3} \mathrm{Ag}_{2} \mathrm{Sb}_{6} \mathrm{~S}_{13}$

2 fizelyite, $\mathrm{Pb}_{5} \mathrm{Ag}_{2} \mathrm{Sb}_{8} \mathrm{~S}_{18}$

3 jamesonite, $\mathrm{FePb}_{4} \mathrm{Sb}_{6} \mathrm{~S}_{14}$

4 andorite, $\mathrm{PbAgSb}_{3} \mathrm{~S}_{6}$

5 rezbanyite, $\mathrm{Pb}_{3} \mathrm{Cu}_{2} \mathrm{Bi}_{10} \mathrm{~S}_{19}$

6 gladite, $\mathrm{PbCuBi}_{5} \mathrm{~S}_{9}$

\footnotetext{
are described in Fig. 7
} 
pyramids, lead atoms being inserted in the large spaces in the framework. In general, in the crystal structures of sulfosalts of this area the linkages of $\mathrm{Cu}$ tetrahedra, or those of $\mathrm{Cu}$ tetrahedra and $\mathrm{TS}_{3}$ pyramids, are closely related to the simple tetrahedral structures observed in sulfides.

Area II covers the silver sulfosalts containing more silver. Although only the crystal structures of pyrargyrite, $\mathrm{Ag}_{3} \mathrm{SbS}_{3}$ (HaRkeR, 1936; Engel and Nowacki, 1966), and xanthoconite, $\mathrm{Ag}_{3} \mathrm{AsS}_{3}$ (ENGEL and

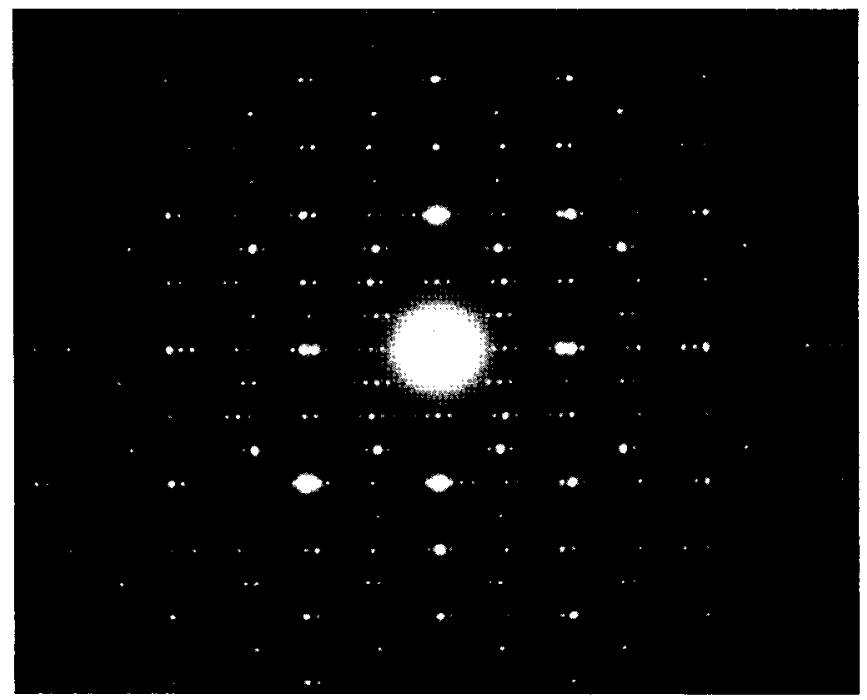

Fig. 4. An electron-diffraction pattern of lengenbachite showing $h k 0$ reflections (taken by $\mathrm{S}$. SuENo). The regular arrangement of stronger reflections indicates the subcell of the galena type

Nowacki, 1968), are known, the crystal structures of these sulfosalts are characterized by covalent bonds which are specific to the silver atoms.

The minerals which fall in the area III, which extends from the central part to the diagram upper to the right, are indicated by solid hexagons. Most of these sulfosalts were investigated by $\mathrm{x}$-ray methods and it has been found that their structures are closely related to the galena-type structure. Matildite, $\mathrm{AgBiS}_{2}$ (GELLER and WernICK, 1959), miargyrite, $\mathrm{AgSbS}_{2}$ (KNowles, 1964), freieslebenite, $\mathrm{PbAgSbS}_{3}$ (HELL$\mathrm{NER}, 1957$ ) and diaphorite, $\mathrm{Pb}_{2} \mathrm{Ag}_{3} \mathrm{Sb}_{3} \mathrm{~S}_{8}$ (HELLNER, 1958) are typical examples. They all are based upon the PbS-type structure, and in fact 
they transform to disordered PbS-type structures at an elevated temperature (WERNICK, 1960). Although in the crystal structure of wallisite (ТАKÉUCHI et al., 1968), which contains copper as a major component, the copper tetrahedra and $\mathrm{AsS}_{3}$ pyramids form a composite chain, the arrangements of lead and sulfur atoms are closely related to the galena structure. Some other minerals in this area, like lengenbachite, $\mathrm{Pb}_{36} \mathrm{Ag}_{7} \mathrm{Cu}_{6} \mathrm{As}_{23} \mathrm{~S}_{78}$, and franckeite, $\mathrm{Pb}_{5} \mathrm{Sn}_{3} \mathrm{Sb}_{2} \mathrm{~S}_{14}$, give diffraction patterns which are characterized by a marked subcell of the galena type (Fig.4), suggesting that, in spite of the complexity of the chemical compositions, the structures are based upon that of galena.

The final area IV, which extends from the lower right part of the diagram to the left, covers the great majority of the lead sulfosalts. Since these are relatively rich in trivalent atoms, they show, in contrast to the singular aspect common to the lead sulfosalts in the area III, various structures depending upon the $\mathrm{Pb}$-to- $\mathrm{T}$ atom ratio. If the ratio is higher, the structures are characterized by the linkage of lead polyhedra while, if the ratio is lower, they are characterized by those of the pyramids of $\mathrm{T}$ atoms. Therefore their structures are primarily to be interpreted in terms of the dimensional differences between lead polyhedra and $T$ pyramids. Thus, from the structural view point, they are the most interesting subgroup of sulfosalts, and the variation of their structures with chemical compositions is discussed below, in terms of the above-mentioned dimensional differences.

With this diagram (Fig. 3) the basic principles of the crystal structure of a given sulfosalt could be predicted, provided that its chemical composition were known. However, this diagram seems to be less applicable to sulfosalts which contain transitional elements as metal atoms. For instance, samsonite, $\operatorname{MnAg}_{4} \mathrm{Sb}_{2} \mathrm{~S}_{6}$ for which $\bar{n}(\mathrm{~A})=4.8$, $\sum n(\mathrm{~A}) / \sum n(\mathrm{~T})=2.4$, falls in the area $\mathrm{I}$, but it is not likely that the structure is characterized by a tetrahedral linkage of metal atoms.

\section{General characteristies of lead sulfosalts}

The most common coordination of lead in sulfides is octahedral, as occurs in galena, the $\mathrm{Pb}-\mathrm{S}$ distance being $2.965 \AA$ (Swanson and Fuyat, 1953). This bond length in galena implies that the edges of the octahedra are $4.19 \AA$ long, provided that the octahedra are of regular shape. This value is longer than the edges in any $\mathrm{TS}_{3}$ pyramids. Therefore sharing edges between octahedra and pyramids inevitably gives rise to a deformation of these polyhedra. Since bonds in pyramids are stronger than those in octahedra, it is expected that the deformations 
are much more conspicuous for octahedra. Greater deformations are evidently to be expected if the lead octahedra share edges with $\mathrm{AsS}_{3}$ pyramids, the smallest. For this case, as shown in Fig.5, the deformations in octahedra produce a fairly large open space which allows further sulfur atoms to approach the central lead atom, thus increasing
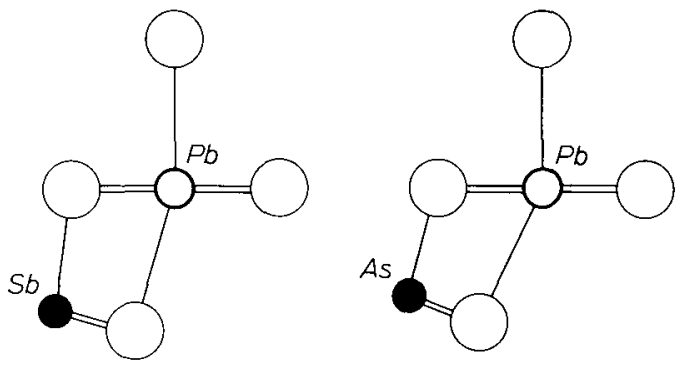

Fig. 5. Deformations of a $\mathrm{Pb}-\mathrm{S}$ octahedron caused by sharing an edge with an $\mathrm{SbS}_{3}$ pyramid (left), and with an $\mathrm{AsS}_{3}$ pyramid (right)

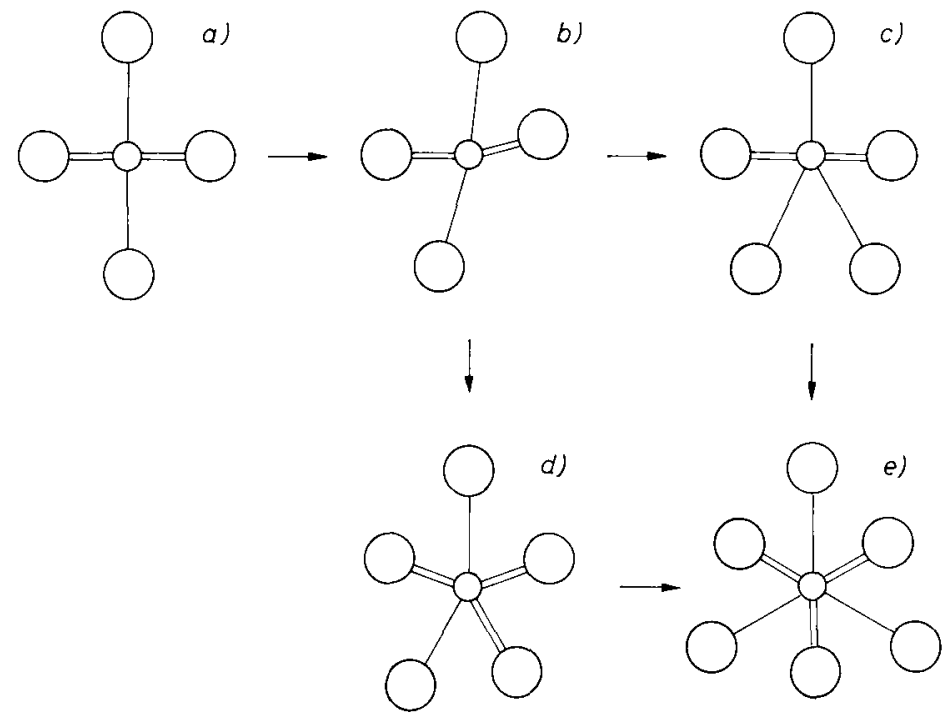

Fig. 6. A regular Pb-S octahedron (a) may be deformed (b) if it shares an edge with a certain $\mathrm{TS}_{3}$ group, producing an open space which allows further sulfur atoms to approach the lead atom. If one sulfur atom approaches, a lead polyhedron of coordination number seven results $(c)$; if two approach, that of coordination number eight is obtained $(d)$. Further deformations of the $\mathrm{Pb}-\mathrm{S}$ polyhedron by sharing edges with $\mathrm{TS}_{3}$ groups finally yield the polyhedron of nine-fold coordination $(e)$ 
the coordination of lead. In fact, in most of the lead sulfarsenites, lead atoms have coordination number nine, which is the highest so far observed for lead. Six of the nine sulfur atoms in such lead polyhedra form, as illustrated in Fig. 6, a trigonal prism whose edges are of lenghts similar to those in lead octahedra and each of the other three sulfur atoms forms a square pyramid on each prism face.

Since $\mathrm{SbS}_{3}$ and $\mathrm{BiS}_{3}$ pyramids cause relatively less distortion of lead octahedra, the lead polyhedra in the structure of sulfantimonites and sulfbismuthites generally take a form intermediate between octahedra and the nine-coordinated polyhedra just mentioned. They may also be distorted octahedra (Fig. 6). The coordination number of lead in these sulfosalts is therefore $6,7,8$. The ratio between the number of octahedra and the number of intermediate polyhedra in a structure depends on the content of lead relative to that of the $T$ atoms.

These relations among the lead sulfosalts can be systematized if we apply the principle discussed in the preceeding section. Using it, we can further classify the lead sulfosalts. We then introduce two parameters: the first is the principal quantum number of the trivalent atoms, $n(\mathrm{~T})$, and the other is $\Sigma n\left(\mathrm{~A}_{i}\right) / \sum n\left(\mathrm{~T}_{j}\right)$ just as the diagram of Fig. 3. Figure 7 is then a diagram in which the second parameter is plotted along the vertical axis and the first along the horizontal. On the left of this diagram there appear only sulfarsenites, in the middle sulfantimonites and on the right sulfbismuthites. The area of this diagram can be roughly divided into three parts according to types of lead polyhedra occurring in the structures.

In the structures of sulfosalts in the upper right area of this diagram, both octahedra and intermediate polyhedra occur, and in those of the central area, only intermediate types. In those of the left part, which covers the sulfarsenites, the nine-fold coordination appears. Among sulfarsenites, hutchinsonite (TAKÉUCHI et al., 1965) which is most rich in arsenic, is somewhat exceptional. Since half of the arsenic atoms of hutchinsonite form a sheet structure, the number of arsenic atoms surrounding lead-sulfur polyhedra is less than in other sulfarsenites. Thus only intermediate polyhedra of lead occur in its structure. With this exception of hutchinsonite, we can observe that, in this diagram, the coordination number of lead increases from the upper right to the lower left.

Such a general tendency in the structures of lead sulfosalts can be explained as follows: As already discussed, bismuth and antimony may have coordination polyhedra which simulate distorted octahedra, 
though bonding is only with the three closest neighbors. These distorted octahedra tend to form, together with lead octahedra, a fragment of the galena-type structure. If the ratio of $\sum n(\mathrm{~A})$ to $\sum n(\mathrm{~T})$ is

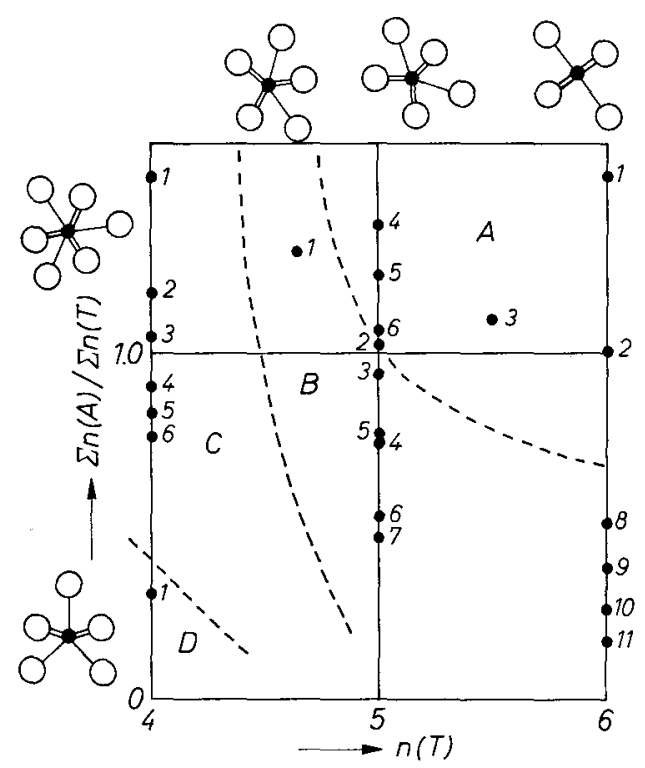

Fig. 7. Relations between chemical compositions and types of lead polyhedra of sulfosalts in the area IV (Fig. 3). Representative minerals are explained below. Since each chemical formula has a general form, $\mathrm{Pb}_{m} \mathrm{~T}_{n} \mathrm{~S}_{p}$, it is given in an abbreviated form, $m n p$. Those which have not the general form are given in full.

Area A

1 lillianite*, 326

2 cosalite, 225

3 kobellite*, 225

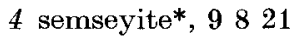

5 boulangerite, 225

6 heteromorphite*, 7819

Area B

1 veenite*, 225

2 fizelyite**

3 jamesonite**

4 andorite**

5 plagionite*, 5817

6 zinkenite, 61427

7 fuloppite*, 3815

* Unknown structure.
8 galenobismutite, 124

9 chiviatite*, 3815

10 bonchevite*, 147

11 ustrasite*, 1610

Area C

1 dufrenoysite, 4410

2 rathite-Ia, 7920

3 rathite-II, 91328

4 rathite-I, 3510

5 baumhauerite, 5918

6 scleroclase, 248

Area D

1 hutchinsonite, $\mathrm{PbTlAs}_{5} \mathrm{~S}_{9}$

** Chemical formula is given in Fig. 3. 
large, the distortions in the fragments may be accomodated locally and the whole structure is of the galena type. On the other hand, if the ratio becomes smaller, the distortions in fragments increase and the extent of the fragments is limited. Therefore, they join in various ways to form a structure. In the boundaries between these fragments, the intermediate type of lead polyhedra occurs (Fig. 8). The occurrence of these intermediate polyhedra (which are not octahedra) presumably plays a role in minimizing the distortions accumulated when the frag-

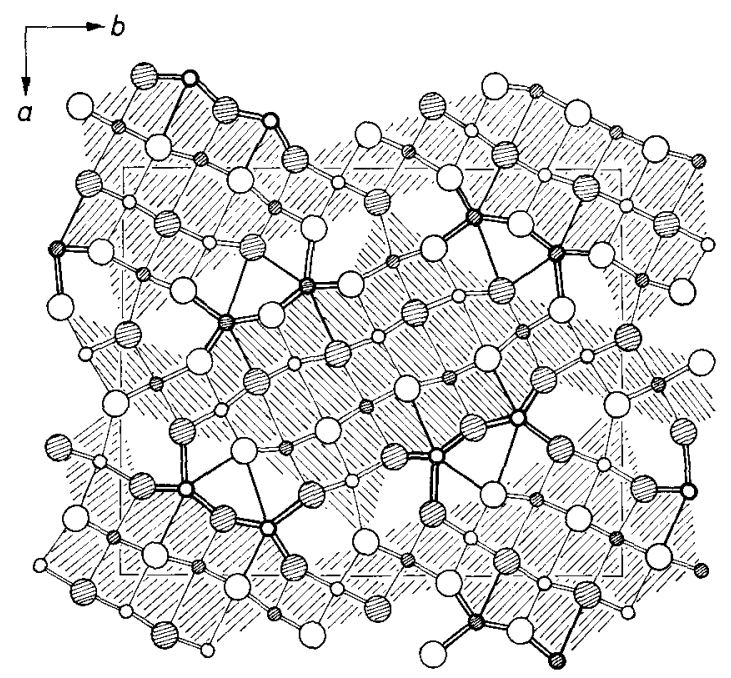

Fig. 8. The crystal structure of cosalite projected along the $c$ axis, showing the fragments of the galena-type structure (shaded area). The bonds of intermediate $\mathrm{Pb}-\mathrm{S}$ polyhedra are indicated by heavy lines. Large circles are sulfur atoms, and small ones in the shaded area are lead or bismuth. The shaded circles and open circles are respectively at $z=3 / 4$ and $z=1 / 4$ [after WEITz and HeLLNer

(1960), but with some changes]

ments are joined. This is the case of sulfosalts in the upper right area of the diagram. Now, as the ratio decreases further, the fragments come to consist solely of trivalent atoms, and the lead atoms occur only in the boundaries of these fragments. This is the case of sulfosalts in the central area of the diagram. Since the pyramids of arsenic atoms have the smallest dimensions, they no longer form structural fragments of the galena type in the structures of sulfarsenites of the left part of the diagram, and lead octahedra are generally highly deformed to have the nine-fold coordination. 
Next, we discuss in a different way the effects of the dimensional differences between pyramids and lead polyhedra. In the structure of lead sulfosalts, the nine-coordinated polyhedra tend to share basal triangles to form an infinite chain, while octahedra share edges and also form an infinite chain (Fig.9). Since both chains have repeat distances of about $4.19 \AA$, the great majority of lead sulfosalts have cell edges of about $4.19 \AA$ or its multiples. Without exception the single repeat distance appears in sulfbismuthites. This is because the $\mathrm{BiS}_{3}$

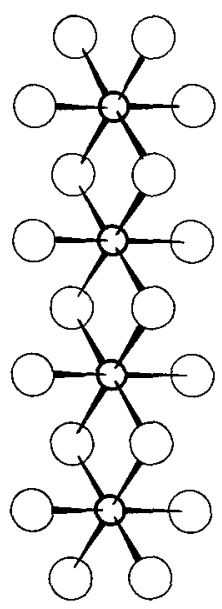

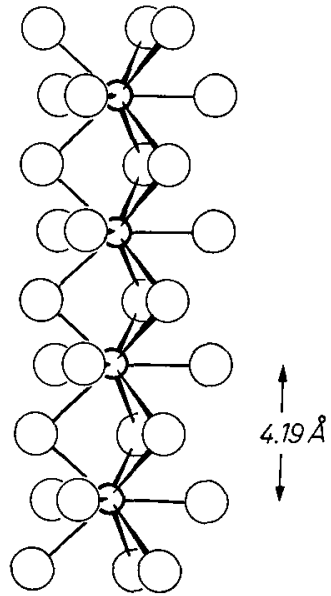

Fig.9

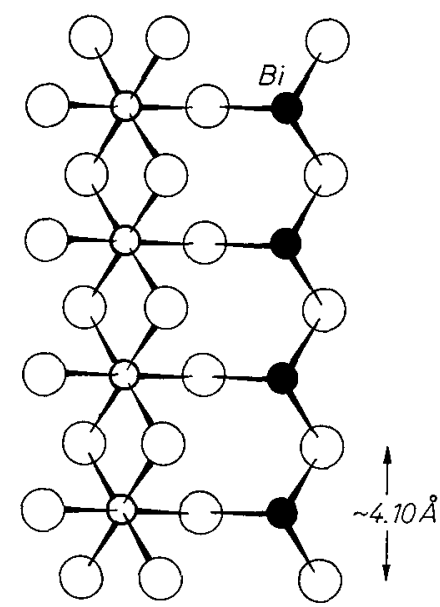

Fig. 10

Fig. 9. Infinite chains of $\mathrm{Pb}-\mathrm{S}$ octahedra (left), and of nine-fold polyhedra (right)

Fig. 10. A chain of $\mathrm{BiS}_{3}$ pyramids along that of $\mathrm{Pb}-\mathrm{S}$ octahedra

pyramids are the largest and their edge lengths are very close to those of lead octahedra. Therefore $\mathrm{BiS}_{3}$ pyramids may share corners and form an infinite chain whose repeat distance is in conformity with that of lead chain. Figure 10 shows the general scheme of how the lead chains and $\mathrm{BiS}_{3}$ chains are connected together. It should be noted that, in sulfbismuthites, the repeat distances along the chain directions are around $4.10 \AA$ and less than the ideal repeat distance of the lead chains. Therefore, the slightly smaller repeat distance of the $\mathrm{BiS}_{3}$ chains presumably causes the shrinkage of lead chains along their lengths.

On the contrary, the single repeat distance never occurs in sulfarsenites but the repeat distances are generally multiple of just about $4.19 \AA$, the ideal value. This is explicable in that the edges of $\mathrm{AsS}_{3}$ 
pyramids are much smaller than those of the lead polyhedra and, thus, for this case of sulfarsenites the formation of infinite chains like $\mathrm{BiS}_{3}$ is not possible but the $\mathrm{AsS}_{3}$ pyrmids form various finite chains along the chain direction of lead polyhedra as given in Fig. 11. The arrangement of these finite chains along lead ehains determines the repeat distance of a structure along the direction of the lead chains, and therefore, the single repeat distance of the lead chains is no longer the true repeat distance in this direction. Since it is conceivable that such a mode of arrangement of finite chains minimizes the deformation of lead chains
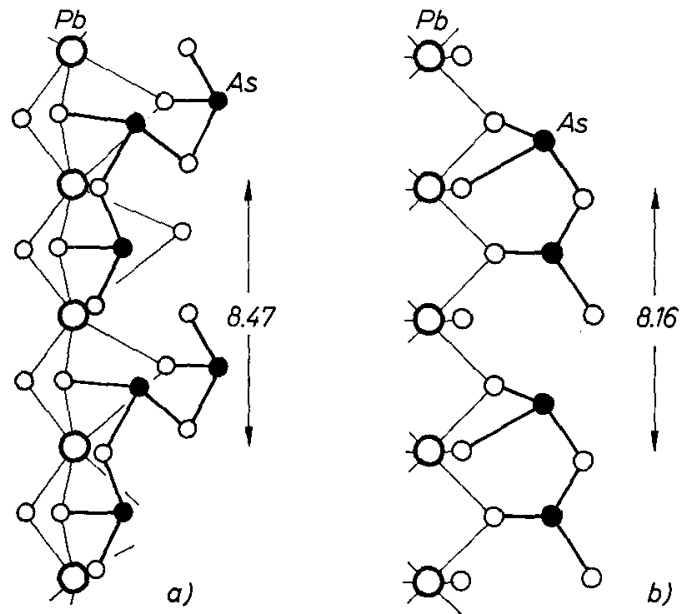

Fig. 11. Finite chains or groups of $\mathrm{AsS}_{3}$ pyramids along $\mathrm{Pb}-\mathrm{S}$ chains. (a) rathite-I, $(b)$ hutchinsonite

along their lengths, the repeat distance of lead chains may retain their ideal value $4.19 \AA$. In this way, it is understandable why the repeat distances of sulfarsenites along the chain direction are multiples of the ideal $4.19 \AA$. The repeat distances or sub-repeat distances along chain directions are compared for sulfbismuthites, sulfantimonites and sulfarsenites in Fig. 12.

The dimensions of $\mathrm{SbS}_{3}$ pyramids are in between those found in the above two cases and, as observed in Fig. 12, the repeat distances along lead chains do not show a characteristic value as do other cases, but are distributed over a wide range. We can observe, in fact, various types of $\mathrm{SbS}_{3}$ linkages in sulfantimonites. They may be divided into three eategories. Firstly, along lead chains $\mathrm{SbS}_{3}$ pyramids form single infinite 
chains like $\mathrm{BiS}_{3}$. Such a configuration of pyramids appears especially in the structures which contain smaller metal atoms like $\mathrm{Fe}$ in addition to lead. Thus this type of chain is observed in berthierite, $\mathrm{FeSb}_{2} \mathrm{~S}_{4}$ (BUERGER and HAHN, 1955), and jamesonite, $\mathrm{FePb}_{4} \mathrm{Sb}_{6} \mathrm{~S}_{4}$ (NIIzeKI and Buerger, 1957b). For these cases, if lead is present, the $\mathrm{Pb}-\mathrm{S}$ chain is

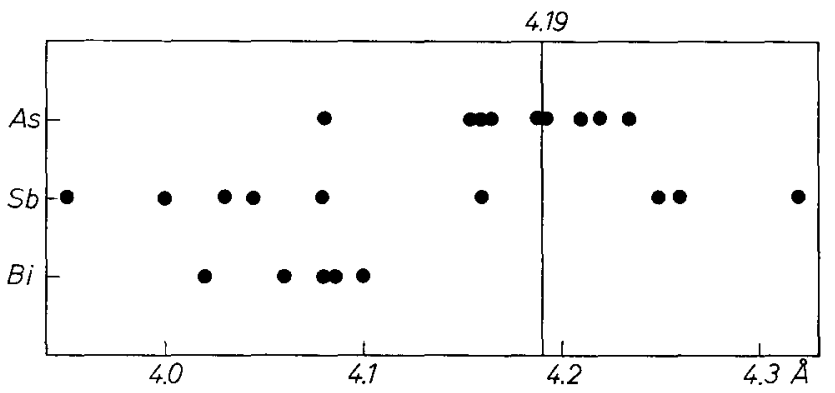

Fig. 12. Comparison of the repeat distances or sub-repeat distances along $\mathrm{Pb}-\mathrm{S}$ chain directions of various sulfarsenites (As), sulfantimonites ( $\mathrm{Sb}$ ), and sulf bismuthites (Bi) in the area IV (Fig.3)

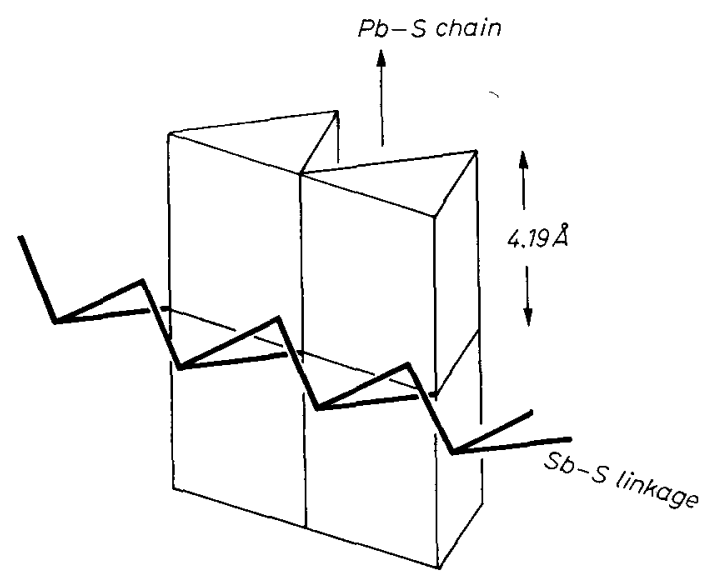

Fig. 13. A schematic illustration of the lateral linkage of $\mathbf{S b S}_{3}$ pyramids with respect to $\mathrm{Pb}-\mathrm{S}$ chains in jamesonite

subject to contraction along the chain direction and shows a smaller repeat distance than $4.19 \AA$. For example, the repeat distance of jamesonite along chain direction is $4.03 \AA$. Secondarily, the pyramids form a complex chain so as to minimize the deformation of $\mathrm{Pb}-\mathrm{S}$ chains. An example of such a chain has been reported for livingstonite, 
$\mathrm{HgSb}_{4} \mathrm{~S}_{8}$ (NIIZEkI and Buerger, 1957 a). Finally, the pyramids form a lateral linkage with respect to lead chains, as two of the three nonequivalent $\mathrm{Sb}$ in jamesonite (Fig. 13). These various possible linkages of $\mathrm{SbS}_{3}$ pyramids may account for the various repeat distances of sulfantimonites along lead chains.

In addition to the lead sulfosalts so far discussed, there are, in area IV of the diagram (Fig.3), a few sulfosalts which contain thallium atoms as $\mathrm{A}$ atoms like lorandite, $\mathrm{TlAsS}_{2}$, and vrbaite, $\mathrm{TlAs}_{2} \mathrm{SbS}_{5}$. However, owing to the fact that thallium atoms tend to form a polyhedron of sulfur atoms which is different from lead-sulfur polyhedra as observed in lorandite (ZEMANN and ZEMANN, 1959), a slight modification of the above discussions would be necessary to extend them to the sulfosalts whose A atoms are solely thallium.

The authors wish to thank Dr. A. L. Mackay for discussions and reading manuscript, and Dr. M. OHMASA for his assistance in computations.

Added in proof: After this paper was sent for publication, Professor Menzer kindly pointed out us a NowACKI's paper presented at the meeting of crystallographers at Bern, October 1968, whose abstract was later published in this journal, Vol. 128 (1969) 427-428 and full paper in Schweizer MineralogischPetrographische Mitteilungen, Vol. 49 (1969) 109-156 under the title ,Zur Klassifikation und Kristallchemie der Sulfosalze". In this paper, NowackI mainly discussed the configurations of anionic groups consisting of TS $_{3}$ pyramids in terms of $\varphi$ value, the ratio of the number of $S$ atoms to that of $T$ atoms in a formula unit. He then showed that possible topological features of the anionic groups are deduced from a given $\varphi$ value.

In connection with our paper, we should also mention a work done by E. Hellner [ A structural scheme for sulfide minerals. J. Geol. 66 (1958) $503-525]$, in which he successfully systematized the structures of sulfides and sulfosalts on the basis of the closest-packings of sulfur atoms. After his work was published, a number of detailed structures have become available, giving an information on the distortions of sulfur lattices mainly due to the formation of $\mathrm{TS}_{3}$ pyramids characteristic of sulfosalts. Since distortion of a structure is an important aspect in erystal chemistry, we placed much stress upon this point.

\section{References}

L. G. Berry (1965), Recent advances in sulfide mineralogy. Amer. Min. 50, $301-313$.

L. G. Berry and Brian Mason (1959), Mineralogy. W. H. Freeman and Co. San Francisco.

M. J. BUERGER and THEODOR HAHN (1955), The crystal structure of berthierite, $\mathrm{FeSb}_{2} \mathrm{~S}_{4}$. Amer. Min. 40, 226-238. 
N. Camerman and J. Trotter (1964), Stereochemistry of arsenic, Part XI. "Cacodyl disulphide", dimethylarsino dimethyldithioarsinate. J. Chem. Soc. [London] $219-227$.

D. W. J. Cruickshank (1964), The rôle of $3 d$ orbitals in $\pi$ bonds between (a) silicon, phosphorus, sulphur, or chlorine and $(b)$ oxygen or nitrogen. J. Chem. Soc. $5486-5504$.

P. ENGEL und W. NowACKI (1966), Die Verfeinerung der Kristallstruktur von Proustit, $\mathrm{Ag}_{3} \mathrm{AsS}_{3}$, und Pyrargyrit, $\mathrm{Ag}_{3} \mathrm{SbS}_{3}$. N. Jahrb. Miner. Monatsh. $181-184$.

P. Engel und W. Nowacki (1968), Die Kristallstruktur von Xanthokon, $\mathrm{Ag}_{3} \mathrm{AsS}_{3}$. Acta Crystallogr. B 24, $77-80$.

S. GELLER and J.H. WERNICK (1959), Ternary semiconducting compounds with sodium chloride structure: AgSbSe $, \mathrm{AgSbTe}_{2}, \mathrm{AgBiS}_{2}, \mathrm{AgBiSe}_{2}$. Acta Crystallogr. 12, $46-54$.

D. Harker (1936), The application of the three-dimensional Patterson method and crystal structures of proustite, $\mathrm{Ag}_{3} \mathrm{AsS}_{3}$, and pyrargyrite, $\mathrm{Ag}_{3} \mathrm{SbS}_{3} . \mathrm{J}$. Chem. Physics 4, 281-390.

Erwin Heltner (1957), Über komplex zusammengesetzte sulfidische Erze, II. Zur Struktur des Freieslebenit, PbAgSbS 3 . Z. Kristallogr. 109, 284-295.

Erwin Hellner (1958), Über komplex zusammengesetzte Spießglanze, III. Zur Struktur des Diaphorits, $\mathrm{Ag}_{3} \mathrm{~Pb}_{2} \mathrm{Sb}_{3} \mathrm{~S}_{8}$. Z. Kristallogr. 110, 169-174.

E. Hellner und G. Leineweber (1956), Über komplex zusammengesetzte sulfidische Erze. I. Zur Struktur des Bournonits, CuPbSbS 3 , und Seligmannits, CuPbAsS 3 . Z. Kristallogr. 107, 150-154.

W. HofmanN (1933), Strukturelle und morphologische Zusammenhänge bei Erzen vom Formeltypus $\mathrm{ABC}_{2}$. I. Die Struktur von Wolfsbergit CuSbS und Emplektit $\mathrm{CuBiS}_{2}$ und deren Beziehung zu der Struktur von Antimonit $\mathrm{Sb}_{2} \mathrm{~S}_{3}$. Z. Kristallogr. 84, 177-203.

Y. IITAKA and W. NowACKI (1962), A redetermination of the crystal structure of galenobismutite, $\mathrm{PbBi}_{2} \mathrm{~S}_{4}$. Acta Crystallogr. 15, 691-698.

Charles R. Knowles (1964), A redetermination of the structure of miargyrite, AgSbS $_{2}$. Acta Crystallogr. 17, 847-851.

G. Leineweber (1956), Struktur-Analyse des Bournonits und Seligmannits mit Hilfe der Superpositions-Methoden. Z. Kristallogr. 108, 161-184.

F. MARUmo (1967), The crystal structure of nowackiite, $\mathrm{Cu}_{6} \mathrm{Zn}_{3} \mathrm{As}_{4} \mathrm{~S}_{12}$. Z. Kristallogr. 124, 352-368.

F. Marumo and W. Nowacki (1966), The crystal structure of rathite-I. Z. Kristallogr. 122, 433-456.

F. Marumo and W. Nowacki (1967), The crystal structure of hatchite, PbTlAgAs $\mathrm{S}_{5}$. Z. Kristallogr. 125, 249-265.

N. Morimoto (1954), The crystal structure of orpiment, $\mathrm{As}_{2} \mathrm{~S}_{3}$, refined. Mineral. Journ. 1, 160-169.

N. Nitzeki and M. J. Buerger (1957a), The crystal structure of livingstonite, $\mathrm{HgSb}_{4} \mathrm{~S}_{8}$. Z. Kristallogr. 109, 129-157.

N. Nitzeki and M. J. BuERGER $(1957 b)$, The erystal structure of jamesonite, $\mathrm{F}_{\ominus} \mathrm{Pb}_{4} \mathrm{Sb}_{6} \mathrm{~S}_{16} . \quad \mathrm{Z}$. Kristallogr. 109, 161-183.

W. B. Pearson (1964), The crystal structures of semiconductors and general valence rule. Acta Crystallogr. 17, 1-15. 
S. Š́AVNIČAR (1960), The crystal structure of stibnite, A redetermination of atomic positions. Z. Kristallogr. 114, 85-97.

H. E. Swanson and R. R. Fuyat (1953), NBS Circular 539, II, 18.

Y. TAkéuChI, S. Ghose and W. NowaCkI (1965), The crystal structure of hutchinsonite, ( $\mathrm{Tl}, \mathrm{Pb})_{2} \mathrm{As}_{5} \mathrm{~S}_{9}$. $\mathrm{Z}$. Kristallogr. 121, 321-348.

Y. TAKéUCHI and N. HagA (1969), On the crystal structures of seligmannite, $\mathrm{PbCuAsS}_{3}$, and related minerals. Z. Kristallogr. 130, 254-260.

Y. TAKéUChI, M. OHMasa and W. Nowacki (1968), The crystal structure of

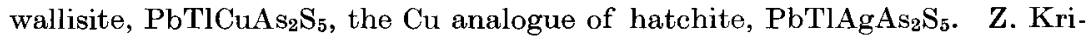
stallogr. 127, 349-365.

G. Weitz und E. HelliNer (1960), Über komplex zusammengesetzte sulfidische Erze. VII. Zur Kristallstruktur des cosalits, $\mathrm{Pb}_{2} \mathrm{Bi}_{2} \mathrm{~S}_{5}$. Z. Kristallogr. 113, $385-402$.

J. H. WeRnick (1960), Constitution of the $\operatorname{AgSbS}_{2}-\mathrm{PbS}, \mathrm{AgBiS}_{2}-\mathrm{PbS}$, and $\mathrm{AgBiS}_{2}-\mathrm{AgBiSe}_{2}$ systems. Amer. Min. 45, 591-598.

BernhardT J. Wuensch (1964), The crystal structure of tetrahedrite, $\mathrm{Cu}_{12} \mathrm{Sb}_{4} \mathrm{~S}_{13}$. Z. Kristallogr. 119, 437-453.

B. J. Wuensch and W. Nowacki (1967), The crystal structure of marrite, $\mathrm{PbAgAsS}_{3}$. Z. Kristallogr. 125, 459-488.

B. J. Wuensch, Y. Takéuchi and W. Nowacki (1966), Refinement of the crystal structure of binnite, $\mathrm{Cu}_{12} \mathrm{As}_{4} \mathrm{~S}_{13}$. Z. Kristallogr. 123, 1-20.

A. Zemann and J.Zemann (1959), Zur Kenntnis der Kristallstruktur von Lorandit, TlAsS ${ }_{2}$. Acta Crystallogr. 12, 1002-1006. 